\title{
Long-term survivorship and complication rate comparison of a cementless modular stem and cementless fixed neck stems for primary total hip replacement
}

\author{
David A. Fitch ${ }^{1}$. Cristina Ancarani ${ }^{2} \cdot$ Barbara Bordini $^{2}$ \\ Received: 19 May 2015 / Accepted: 20 June 2015 / Published online: 9 July 2015 \\ (C) The Author(s) 2015. This article is published with open access at Springerlink.com
}

\begin{abstract}
Purpose Modular necks used in total hip replacement (THR) have become an increasingly discussed topic with the recent recall of multiple modular systems, but it is anticipated that outcomes for these devices are highly design-specific. The objectives of this study were to determine if the survivorship and complication rates of a specific modular femoral stem (PROFEMUR ${ }^{\circledR}$ Z, MicroPort Orthopedics Inc., Arlington, TN, USA) were significantly lower than those of all cementless fixed neck stems in an arthroplasty registry.

Methods The database of an arthroplasty registry was searched for all patients implanted with a specific modular stem and all those implanted with cementless fixed neck stems. Kaplan-Meier survivorship and complication rates were compared between the two groups.

Results The 12-year survivorship of the modular stem $(95.8 \%)$ was not significantly less than that of all cementless fixed neck stems $(96.1 \%)$. There was also no difference in revision rates for dislocation, periprosthetic fractures, aseptic loosening or septic loosening between the two groups.

Conclusions The use of the specific modular stem did not adversely affect long-term component survivorship or complication rates when compared to all cementless fixed neck THRs in an arthroplasty registry.
\end{abstract}

Keywords Exchangeable necks · Modular necks · Total hip arthroplasty · Total hip replacement

David A. Fitch

david.fitch@ortho.microport.com

1 MicroPort Orthopedics Inc, 5677 Airline Rd., Arlington, TN 38002, USA

2 Istituto Ortopedico Rizzoli, Bologna, Italy

\section{Introduction}

Modularity in total hip replacement (THR) was introduced to provide surgeons with increased flexibility to more closely recreate individual patient anatomy. Femoral stems with modular necks, when compared to fixed neck stems, can allow for finer adjustment of leg length, version, offset, head centre and neck-shaft angle while also decreasing required implant inventory. Replicating these factors is important for routine THR patients, but can also be of particular benefit to those with difficult anatomies (e.g. developmental dysplasia) [1]

While there are numerous potential benefits of modular femoral stems, the presence of the modular neck-femoral stem taper junction does introduce the possibility of additional failure modes including modular neck fracture and adverse local tissue reactions resulting from corrosion and wear debris. The recent voluntary recall of the Rejuvenate and ABG II Modular Hip Systems (Stryker Orthopaedics, Mahwah, NJ, USA) [2] and reports of higher revision rates for modular devices in the Australian Orthopaedic Association National Joint Replacement Registry [3] have raised concerns about the use of modular femoral stems. Despite these concerns, recent society presentations have urged caution when treating all modular designs the same [4-6]. There are differences in taper designs, materials and other factors with the potential to significantly affect outcomes. For example, the titaniummolybdenum-zirconium-iron (TMZF) alloy used for the Rejuvenate and ABG II modular stems has different material characteristics than the titanium-aluminum-vanadium (Ti 6Al $4 \mathrm{~V}$ ) alloy traditionally used for cementless femoral stems.

The primary objective of this study was to determine if the component survivorship of a specific modular femoral stem, the PROFEMUR ${ }^{\circledR} \mathrm{Z}$ (MicroPort Orthopedics Inc., Arlington, TN, USA), was significantly lower than that of cementless fixed neck stems. The secondary objective was to determine if there 
was a significant difference in complication rates for this modular stem compared to that of cementless fixed necks stems.

\section{Methods}

\section{Data source}

The Register of Orthopaedic Prosthetic Implants (RIPO) was initiated in 1990 at the Istituto Ortopedico Rizzoli in the Emilia-Romagna region of Italy [7, 8]. By January 2000, all 68 orthopaedic units (59 hospitals) in the region had begun contributing data. While the RIPO is technically a regional register, the Emilia-Romagna region has a population of nearly 4.5 million, similar in size to that available to several national arthroplasty registers (e.g. the Danish Arthroplasty Register, Norwegian Arthroplasty Register and New Zealand Joint Registry). The RIPO database consists of relevant patient information for both primary and revision THR and knee replacement including: demographics, surgical procedure details, implant types identified by product code, implant fixation and reasons for revision. In 2013, the RIPO captured $98 \%$ of hip and knee procedures performed in the region.

\section{Database search}

On 2 January 2015, the database was searched for all PROFEMUR ${ }^{\circledR} \mathrm{Z}$ modular femoral stems implanted between 1 January 2000 and 31 December 2012. This cementless stem has a rectangular cross-section and dual taper geometry (Fig. 1). It is manufactured from a $\mathrm{Ti} 6 \mathrm{Al} 4 \mathrm{~V}$ alloy with a heavy grit blast surface finish ( $8 \mathrm{Ra} \mu \mathrm{m})$ and features a 12/ 14 modular neck-femoral stem taper junction.

Patients were included in the analysis if they had a primary THR with the subject stem as identified by product code. Patients were excluded if they lived outside of the EmiliaRomagna region to minimise bias due to loss to follow-up. All articulation couples (including metal-on-metal), acetabular combinations and indications for implantation were included in the final analysis. For the same time period, all fixed neck femoral stems implanted with cementless fixation were also identified as a reference for component survivorship comparison. The previously described criteria for inclusion, with the exception of product code identification, were also applied to this group.

\section{Statistics}

SPSS software (version 14.0.1, Chicago, IL, USA) was used for all statistical analyses. Available patient demographics and reasons for revision were presented as percentages of the total cohort. Survivorship analysis was performed using KaplanMeier analysis with revision of the stem and/or the modular neck as the endpoint; $95 \%$ confidence intervals (CI) were also

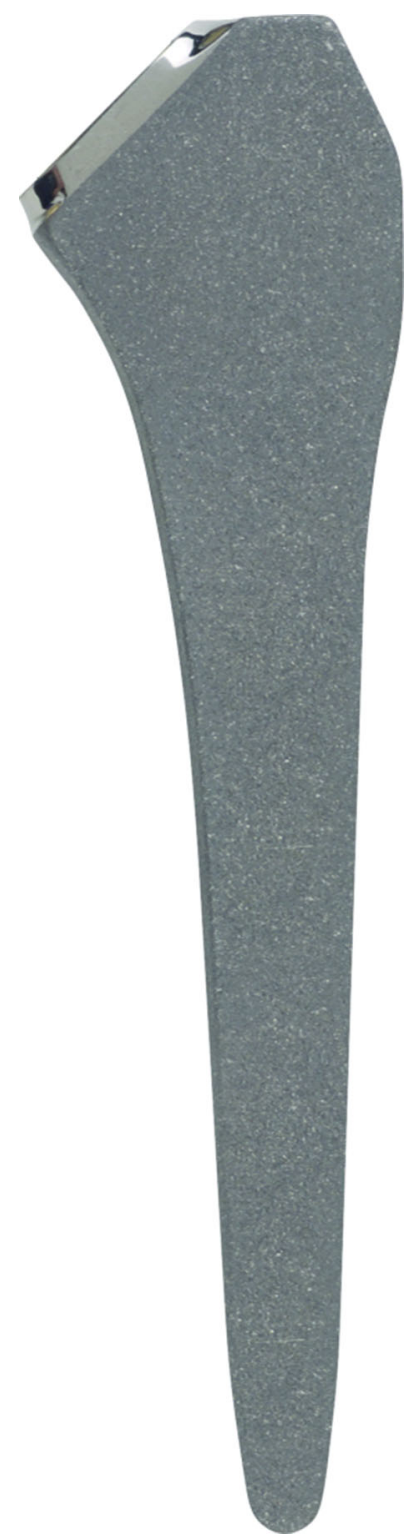

Fig. 1 PROFEMUR ${ }^{\circledR} \mathrm{Z}$ modular stems (image used courtesy of MicroPort Orthopedics Inc.)

calculated. The survival times of unrevised stems were taken at the last date of observation (date of death or 31 December 2012). A Wilcoxon test and Cox regression analysis were used to compare survivorship and complication rates (dislocation, periprosthetic fracture, aseptic loosening and septic loosening) between the two groups.

\section{Results}

A total of 692 primary THRs using the PROFEMUR ${ }^{\circledR} \mathrm{Z}$ modular femoral stems were performed during the relevant time period. The mean follow-up was 9.0 years (range 0.02 13.6). Of the 68 orthopaedic units included in the RIPO, 26 had implanted the subject stem. The average patient age was 
64.1 years (range 24-90) and more than half were female (Table 1). The majority of patients were implanted due to primary osteoarthritis $(71.8 \%)$, but a high percentage $(10.2 \%)$ was implanted due to osteoarthritis secondary to developmental dysplasia. This is partly because there is a high incidence of this condition in the region and the Istituto Ortopedico Rizzoli specialises in this field [9]. The majority of patients included in the analysis were implanted with 28$\mathrm{mm}$ ceramic femoral heads $(83.0 \%)$ in combination with either ceramic $(49.7 \%)$ or polyethylene $(33.3 \%)$ liners (Table 2). All stems and $98.4 \%$ of acetabular components were implanted using cementless fixation. Intra-operative complications were rare $(1.4 \%)$, with fracture of the diaphysis being the most common at $0.6 \%$.

There were 27 revisions for a cumulative revision rate of $3.9 \%$ (Table 3). The most common reasons for revision were recurrent dislocation $(1.3 \%)$ and aseptic stem loosening $(1.2 \%)$. There were no revisions specified as being for adverse local tissue reactions or leg length discrepancy. The overall Kaplan-Meier survivorship was $95.8 \%$ (95\% CI 94.2-97.4) at 12 years of follow-up (Table 4 and Fig. 2). This was compared to the Kaplan-Meier survivorship for all fixed neck stems implanted with cementless fixation $(96.1 \%$ at 12 years) and found to not be significantly different $(p=$ 0.359 ). The survivorship comparison was repeated adjusting for risk of death and there was again no significant difference. There were also no significant differences in revisions for dislocation $(p=0.068)$, periprosthetic fracture $(p=0.584)$, aseptic loosening $(p=0.397)$ or septic loosening $(p=0.537)$.
Table 2 Articulation couples, femoral head size and implant fixation for patients implanted with the PROFEMUR ${ }^{\circledR} \mathrm{Z}$ modular stems

\begin{tabular}{ll}
\hline Articulation couple & \\
Ceramic-on-ceramic & $49.7 \%$ \\
Ceramic-on-polyethylene & $32.0 \%$ \\
Metal-on-polyethylene & $15.1 \%$ \\
Metal-on-metal & $1.4 \%$ \\
Ceramic-on-cross-linked polyethylene & $1.3 \%$ \\
Not available & $0.2 \%$ \\
Femoral head size & \\
$22 \mathrm{~mm}$ & $0.3 \%$ \\
$28 \mathrm{~mm}$ & $87.4 \%$ \\
$32 \mathrm{~mm}$ & $7.2 \%$ \\
$36 \mathrm{~mm}$ & $4.1 \%$ \\
$\geq 38 \mathrm{~mm}$ & $1.0 \%$ \\
Implant fixation & \\
Cementless stem and cup & $98.4 \%$ \\
Cementless stem and cemented cup & $1.6 \%$ \\
\hline
\end{tabular}

\section{Discussion}

\section{Survivorship}

At 12 years, the component survivorship for the subject stems was $95.8 \%$ (95\% CI 94.2-97.4), which was not significantly different than that for all cementless fixed neck stems implanted during the same time period. These data suggest that

Table 1 Demographics and intra-operative complications for patients implanted with the PROFEMUR ${ }^{\circledR} \mathrm{Z}$ modular stems and the cementless fixed neck THRs

\begin{tabular}{|c|c|c|}
\hline & PROFEMUR ${ }^{\circledR} \mathrm{Z}$ & Cementless fixed neck THRs \\
\hline Male/female & $43 / 57 \%$ & $41 / 59 \%$ \\
\hline Mean age & 64.1 years (range $24-90$ ) & 67.7 years (range $(14-100)$ \\
\hline \multicolumn{3}{|l|}{ Body mass index, $\mathrm{kg} / \mathrm{m}^{2}$} \\
\hline Underweight $(<19)$ & $1.2 \%$ & $1.0 \%$ \\
\hline Normal (20-25) & $36.7 \%$ & $35.3 \%$ \\
\hline Overweight (26-29) & $44.5 \%$ & $45.3 \%$ \\
\hline Obese $(>30)$ & $17.6 \%$ & $18.4 \%$ \\
\hline \multicolumn{3}{|l|}{ Indication for THR } \\
\hline Primary osteoarthritis & $71.8 \%$ & $69.8 \%$ \\
\hline Osteoarthritis secondary to developmental dysplasia & $10.2 \%$ & $8.9 \%$ \\
\hline Femoral head necrosis & $6.0 \%$ & $5.7 \%$ \\
\hline Femoral neck fracture & $5.7 \%$ & $10.6 \%$ \\
\hline Other & $6.2 \%$ & $5.0 \%$ \\
\hline \multicolumn{3}{|l|}{ Intra-operative complications } \\
\hline Fracture of femur diaphysis & $0.6 \%$ & $0.3 \%$ \\
\hline Calcar fracture & $0.4 \%$ & $0.5 \%$ \\
\hline Anaesthesiology complications & $0.3 \%$ & $0.13 \%$ \\
\hline Fracture of the acetabulum & $0.1 \%$ & $0.14 \%$ \\
\hline
\end{tabular}


Table 3 Reasons for revision of patients implanted with the PROFEMUR ${ }^{\circledR} Z$ modular stems

\begin{tabular}{lll}
\hline Reasons for revision & $n$ & $\%$ \\
\hline Recurrent dislocation & 9 & 1.3 \\
Aseptic stem loosening & 8 & 1.2 \\
Periprosthetic bone fracture & 3 & 0.4 \\
Breakage of femoral head & 2 & 0.3 \\
Breakage of modular neck & 2 & 0.3 \\
Septic loosening & 1 & 0.1 \\
Aseptic loosening & 1 & 0.1 \\
Pain without loosening & 1 & 0.1 \\
Total & 27 & 3.9 \\
\hline
\end{tabular}

there is not an increased risk of revision at long-term followup when using the subject modular stem. This survivorship estimate is also sufficient to satisfy the recommendations of the National Institute for Health and Care Excellence (NICE) in the UK [10]. These guidelines recommend that only THR and resurfacing devices with revision rates of $5 \%$ or less at ten years of follow-up should be used by clinicians.

A literature review returned a single publication on a series of patients implanted with the subject modular stems [11]. This single-surgeon series reported a component survivorship estimate of $89.4 \%$ at eight years, but caution should be used in interpreting the results due to several limitations. The mean follow-up was only 4.5 years (range $2-9$ years), suggesting a minimal number of THRs were available at the later follow-up when survivorship was reported. This can amplify the impact of revisions on survivorship estimates at later follow-up times, which is possibly illustrated in a figure in the report showing a single revision occurring at 7.2 years decreased the survivorship estimate by approximately $5 \%$. In contrast, the survivorship estimate at the mean follow-up of 4.5 years can be estimated from the same figure as $98 \%$. A second possible

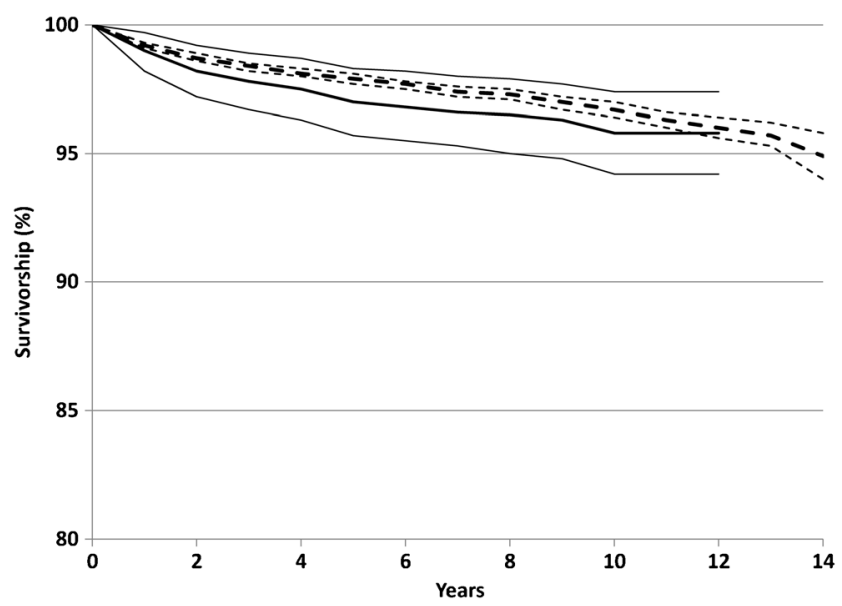

Fig. 2 Kaplan-Meier survivorship for the PROFEMUR ${ }^{\circledR} \mathrm{Z}$ modular stems (solid black line) and all cementless fixed neck stems (dashed black line) was not statistically different at 12 years

confounding factor was the high number of metal-on-metal articulations (49\%) included in the analysis.

\section{Dislocation rate}

Complication rates, including the dislocation rate, for the subject modular stems were not significantly different than those for all cementless fixed neck stems. While theoretically modular necks should reduce dislocation rates, this finding is not entirely unexpected as nearly $90 \%$ of patients implanted with the subject stem had femoral heads sized $28 \mathrm{~mm}$ or smaller. A review of the Norwegian Arthroplasty Register reported that patients with $28-\mathrm{mm}$ femoral heads were four times more likely to dislocate when compared to those with $32-\mathrm{mm}$ femoral heads [12]. Of the nine revisions for dislocation in the PROFEMUR ${ }^{\circledR} \mathrm{Z}$ modular stem cohort, eight $(88.9 \%)$ occurred in patients implanted with $28-\mathrm{mm}$ femoral heads.

Table 4 Survivorship and number at risk for the PROFEMUR ${ }^{\circledR} \mathrm{Z}$ modular stems

\begin{tabular}{lllllll}
\hline Year & Survivorship (\%) & Lower $95 \%$ CI & Upper 95 \% CI & No. of revisions & No. of deaths & No. of exposed risks \\
\hline 0 & 100.0 & 100.0 & 100.0 & 7 & 5 & 687 \\
1 & 99.0 & 98.2 & 99.7 & 5 & 12 & 665 \\
2 & 98.2 & 97.2 & 99.2 & 3 & 5 & 639 \\
3 & 97.8 & 96.7 & 98.9 & 2 & 5 & 615 \\
4 & 97.5 & 96.3 & 98.7 & 3 & 5 & 599 \\
5 & 97.0 & 95.7 & 98.3 & 1 & 12 & 586 \\
6 & 96.8 & 95.5 & 98.2 & 1 & 11 & 572 \\
7 & 96.6 & 95.3 & 98.0 & 1 & 9 & 557 \\
8 & 96.5 & 95.0 & 97.9 & 2 & 14 & 526 \\
9 & 96.3 & 94.8 & 97.7 & 0 & 10 & 390 \\
10 & 95.8 & 94.2 & 97.4 & 0 & 3 & \\
11 & 95.8 & 94.2 & 97.4 & 1 & 1 & 79 \\
\end{tabular}


When examining only patients with potentially difficult anatomies (e.g. developmental dysplasia), there were no revisions for dislocation in patients with the subject stems.

\section{Modular neck fractures}

There have been several case reports describing modular neck fractures with the subject stem [13-18]. In each report, the patient was a large man with a mean weight and body mass index (BMI) of $111.1 \mathrm{~kg}$ and $31.5 \mathrm{~kg} / \mathrm{m}^{2}$, respectively. In this study, there were two modular neck fractures for a rate of $0.3 \%$. The first fracture occurred in a 69 -year-old man with a BMI in the overweight range at 1.4 years of follow-up. The second fracture occurred in a 66-year-old man, also classified as overweight by BMI, at 4.7 years. Both patients were implanted with ceramic-on-polyethylene articulation couples and both with long titanium alloy (Ti 6Al 4V) modular necks. No fractures occurred in patients with short modular necks manufactured from the same titanium alloy.

The modular neck fracture rate described in this study $(0.3 \%)$ compares favourably to the previously described study by Silverton et al. that reported a single modular neck fracture $(0.66 \%)$ [11]. Similar to our study and previous case reports, the modular neck fracture in that study occurred in a large (BMI $38.9 \mathrm{~kg} / \mathrm{m}^{2}$ ) male patient. Other mid- to long-term studies using modular necks from the same manufacturer in combination with different stem designs have also reported low modular neck fracture rates. Omlor et al. reported a single modular neck fracture in 190 THRs $(0.5 \%)$ and Kaplan-Meier survivorship estimates of 99 and $100 \%$ for the same modular necks and a different stem design, respectively, at ten years of follow-up [19]. Blakey et al. reported no modular neck fractures for over 350 THRs and a Kaplan-Meier survivorship estimate of $97.5 \%$ at 5 years [20]. Similarly, Traina et al. reported no modular neck fractures in 88 THRs with a mean follow-up of nine years [21]. Pattyn et al. also reported no modular neck fractures for 68 revision THRs performed using a revision femoral stem from the same manufacturer with identical modular necks [22]. These results suggest that modular neck fracture is not a prominent failure mode for the subject femoral stem or modular neck design.

\section{Limitations}

Despite being a long-term review of a large number of THRs, there are some limitations to this study. The study is a retrospective review of registry data, which has inherent limitations. The complication rates were calculated based upon revisions for specified reasons and could therefore underestimate the occurrence rates, as not all instances of some complications require revision.

\section{Conclusion}

Results from this study suggest that the subject stems are not associated with significantly lower survivorship rates than those of cementless fixed neck stems and that the described survivorship rates with these stems satisfy the recommendations of NICE in the UK. There were no differences in complication rates for any of the most common reasons for revision. Additionally, there were only two modular neck fractures $(0.3 \%)$, further suggesting this is not a prominent failure with this design of modular necks. There were no revisions for adverse local tissue reactions or leg length discrepancy.

Conflict of interest One author (DF) is an employee of MicroPort Orthopedics Inc.

Open AccessThis article is distributed under the terms of the Creative Commons Attribution 4.0 International License (http:// creativecommons.org/licenses/by/4.0/), which permits unrestricted use, distribution, and reproduction in any medium, provided you give appropriate credit to the original author(s) and the source, provide a link to the Creative Commons license, and indicate if changes were made.

\section{References}

1. Traina F, De Fine M, Tassinari E, Sudanese A, Calderoni PP, Toni A (2011) Modular neck prostheses in DDH patients: 11-year results. J Orthop Sci 16(1):14-20. doi:10.1007/s00776-010-0018-y

2. Rejuvenate Modular / ABG II Modular-Neck Stem Voluntary Recall. http://www.stryker.com/en-us/products/Orthopaedics/ modularneckstems/index.htm. Accessed 16 Feb 2015

3. Australian Orthopaedic Association Annual Report. http://aoanjrr. dmac.adelaide.edu.au/. Accessed 16 Feb 2015

4. Cameron HU (2010) The proximal modular neck in THA: a bridge too far: opposes. Orthopedics 33(9):641. doi:10.3928/0147744720100722-27

5. Keggi JM (2014) Femoral neck modularity: a bridge too far-opposes. Semin Arthroplasty 25(2):99-102

6. Murphy S (2013) Femoral neck modularity: a bridge too far - opposes. Bone Joint J 95-B(Suppl 22):5

7. Register of Orthopaedic Prosthetic Implants Annual Report. https:// ripo.cineca.it. Accessed 9 Jan 2015

8. Stea S, Bordini B, De Clerico M, Petropulacos K, Toni A (2009) First hip arthroplasty register in Italy: 55,000 cases and 7 year follow-up. Int Orthop 33(2):339-346. doi:10.1007/s00264-007-0465-z

9. Stea S, Bordini B, Sudanese A, Toni A (2002) Registration of hip prostheses at the Rizzoli Institute. 11 years' experience. Acta Orthop Scand Suppl 73(305):40-44

10. Total hip replacement and resurfacing arthroplasty for end-stage arthritis of the hip (review of technology appraisal guidance 2 and 44) (2014). NICE Technology Appraisal Guidance 304

11. Silverton CD, Jacobs JJ, Devitt JW, Cooper HJ (2014) Midterm results of a femoral stem with a modular neck design: clinical outcomes and metal ion analysis. J Arthroplasty 29(9):1768-1773. doi: 10.1016/j.arth.2014.04.039

12. Byström S, Espehaug B, Furnes O, Havelin LI, Norwegian Arthroplasty Register (2003) Femoral head size is a risk factor for total hip luxation: a study of 42,987 primary hip arthroplasties from 
the Norwegian Arthroplasty Register. Acta Orthop Scand 74(5): 514-524. doi:10.1080/00016470310017893

13. Atwood SA, Patten EW, Bozic KJ, Pruitt LA, Ries MD (2010) Corrosion-induced fracture of a double-modular hip prosthesis: a case report. J Bone Joint Surg Am 92(6):1522-1525. doi:10.2106/ JBJS.I.00980

14. Skendzel JG, Blaha JD, Urquhart AG (2011) Total hip arthroplasty modular neck failure. J Arthroplasty 26(2):338.e1-338.e4. doi:10. 1016/j.arth.2010.03.011

15. Ellman MB, Levine BR (2013) Fracture of the modular femoral neck component in total hip arthroplasty. J Arthroplasty 28(1): 196.e1-196.e5

16. Dangles CJ, Altstetter CJ (2010) Failure of the modular neck in a total hip arthroplasty. J Arthroplasty 25(7):1169.e5-1169.e7. doi: 10.1016/j.arth.2009.07.015

17. Wright G, Sporer S, Urban R, Jacobs J (2010) Fracture of a modular femoral neck after total hip arthroplasty: a case report. J Bone Joint Surg Am 92(6):1518-1521. doi:10.2106/JBJS.I.01033
18. Wilson DA, Dunbar MJ, Amirault JD, Farhat Z (2010) Early failure of a modular femoral neck total hip arthroplasty component: a case report. J Bone Joint Surg Am 92(6):1514-1517. doi:10.2106/JBJS.I.01107

19. Omlor GW, Ullrich $\mathrm{H}$, Krahmer K, Jung A, Aldinger G, Aldinger $P$ (2010) A stature-specific concept for uncemented, primary total hip arthroplasty. Acta Orthop 81(1):126-133. doi:10.3109/ 17453671003587077

20. Blakey CM, Eswaramoorthy VK, Hamilton LC, Biant LC, Field RE (2009) Mid-term results of the modular ANCA-Fit femoral component in total hip replacement. J Bone Joint Surg Br 91(12): 1561-1565. doi:10.1302/0301-620X.91B12.22638

21. Traina F, De Fine M, Biondi F, Tassinari E, Galvani A, Toni A (2009) The influence of the centre of rotation on implant survival using a modular stem hip prosthesis. Int Orthop 33(6):1513-1518. doi:10.1007/s00264-008-0710-0

22. Pattyn C, Mulliez A, Verdonk R, Audenaert E (2012) Revision hip arthroplasty using a cementless modular tapered stem. Int Orthop 36(1):35-41. doi:10.1007/s00264-011-1299-2 